\title{
Intervalo de aplicação de óleos essenciais no controle da mancha bacteriana do tomateiro
}

\author{
Vitor Cabral Araújo ${ }^{1} \oplus$, Nilvanira Donizete Tebaldi²®
}

${ }^{1}$ Graduando em Agronomia, Bolsista de Iniciação Científica, CNPq. Instituto de Ciências Agrárias, da Universidade Federal de Uberlândia, Av. Amazonas s/n, Bloco 2E-119, Campus Umuarama, CEP 38.400-902, Uberlândia, MG, Brasil; ${ }^{2}$ Professora Associada, do Instituto de Ciências Agrárias, da Universidade Federal de Uberlândia, Av. Amazonas s/n, Bloco 2E-119, Campus Umuarama, CEP 38.400-902, Uberlândia, MG, Brasil Autor para correspondência: Nilvanira Donizete Tebaldi (nilvanira.tebaldi@ufu.br)

Data da submissão: 25/10/2017. Aceito para publicação em: 04/02/2019.

$10.1590 / 0100-5405 / 187031$

\section{RESUMO}

Araújo V.C., Tebaldi, N.D. Intervalo de aplicação de óleos essenciais no controle da mancha bacteriana do tomateiro. Summa Phytopathologica, v.45, n.2, p.210-212, 2019.

A mancha bacteriana do tomateiro, causada Xanthomonas spp. pode provocar perdas significativas na produção da cultura. O controle da doença é difícil e produtos alternativos devem ser avaliados. Portanto, os objetivos do trabalho foram avaliar a inibição do crescimento de Xanthomonas spp. in vitro e o intervalo de aplicação de óleos essenciais, no controle da mancha bacteriana do tomateiro. Para avaliação do halo de inibição do crescimento de Xanthomonas spp. in vitro foram empregados óleos essenciais de cravo da índia (Syzygium aromaticum) e erva cidreira (Melissa officinalis), Tween $20 \%$, hidróxido de cobre e água. Para o controle da mancha bacteriana, plantas de tomate foram inicialmente pulverizadas com os produtos; três dias após foram inoculadas por aspersão com

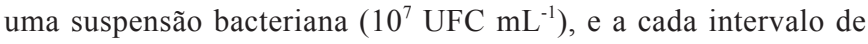
3, 6, 9 ou 12 dias, as plantas foram novamente pulverizadas com os produtos. A severidade da doença foi avaliada, calculando-se a área abaixo da curva de progresso da severidade da doença. Os óleos essenciais de cravo da índia e erva cidreira, e o hidróxido de cobre, nas concentrações 100 e $10 \%$ inibiram o crescimento de Xanthomonas spp. in vitro. Da mesma forma, os óleos essenciais quando aplicados em intervalos de três e seis dias reduziram a severidade da mancha bacteriana do tomateiro, sendo promissores no controle da doença.

Palavras-chave: Cravo da índia, erva cidreira, proteção, Solanum lycopersicum, Xanthomonas spp.

\section{ABSTRACT}

Araújo V.C., Tebaldi, N.D. Interval of essential oil application on tomato bacterial leaf spot control.Summa Phytopathologica, v.45, n.2, p.210212, 2019.

Tomato bacterial leaf spot, caused by Xanthomonas spp., can cause significant losses in the crop production. Disease control is difficult and alternative products should be evaluated. Therefore, the objectives of this study were to evaluate Xanthomonas spp. growth inhibition in vitro and to assess the interval of essential oil application on tomato bacterial leaf spot control. To evaluate the growth inhibition halo for Xanthomonas spp. in vitro, clove (Syzygium aromaticum) and lemon balm (Melissa officinalis) essential oils were used, as well as Tween 20\%, copper hydroxide and water. For bacterial leaf spot control, tomato plants were initially sprayed with those products; three days later, the plants were inoculated by spraying with a bacterial suspension $\left(10^{7} \mathrm{CFU} \mathrm{mL}^{-1}\right)$, and at each interval of 3, 6, 9 or 12 days, the plants were sprayed again with the products. Disease severity was assessed by calculating the area under the disease severity progression curve. Essential oils of clove and lemon balm, and copper hydroxide, at the concentrations of 100 and $10 \%$, inhibited the growth of Xanthomonas spp. in vitro. Similarly, the essential oils reduced the severity of tomato bacterial leaf spot when applied at three- and six-day intervals, showing to be promising in disease control.

Keywords: Clove, lemon balm, protection, Solanum lycopersicum, Xanthomonas spp.

A mancha bacteriana do tomateiro causada por Xanthomonas euvesicatoria, X. vesicatoria, X. gardneri e X. perforans (3) pode ocasionar perdas significativas na produção da cultura, principalmente em condições de elevada umidade e temperatura entre 20 e $30^{\circ} \mathrm{C}(5)$.

O controle químico do patógeno não é eficiente (8) e métodos alternativos devem ser avaliados para o controle da bactéria. Neste contexto, o uso de óleos essenciais mostrou-se promissor para o controle de Alternaria solani, Xanthomonas spp. e Pseudomonas syringae pv. tomato $(1,4,6,11)$ em tomateiro.

Plantas de tomate quando pulverizadas com o óleo essencial cravo da índia e inoculadas com Xanthomonas spp. foi observado um aumento das enzimas peroxidase, quitinase e glucanase e a lignificação da parede celular, indicando a ativação do mecanismo de defesa da planta (6). Em contra partida, o efeito protetor de um indutor de resistência pode durar desde poucos dias até algumas semanas (9).

Os óleos essenciais são produtos naturais, com ação antimicrobiana e não causam impacto ambiental, como os agroquímicos; sendo uma alternativa para o controle de doenças. Portanto, os objetivos deste trabalho foram avaliar a inibição do crescimento de Xanthomonas spp. in vitro e o intervalo de aplicação de óleos essenciais, no controle da mancha bacteriana do tomateiro, em casa de vegetação.

O experimento foi conduzido no Laboratório de Bacteriologia Vegetal (LABAC) e em casa de vegetação, do Instituto de Ciências Agrárias, da Universidade Federal de Uberlândia - MG, no ano de 
2017. O isolado UFU A35 de Xanthomonas spp. pertencente à coleção de trabalho do LABAC foi cultivado em meio de cultura 523. Após 48 $\mathrm{h}$ foi preparada uma suspensão bacteriana em solução de $\mathrm{NaCl} 0,85 \%$ e ajustada em espectrofotômetro para $\mathrm{OD}_{550}=0,5\left(10^{9} \mathrm{UFC} \mathrm{mL}^{-1}\right)$.

Para avaliação do halo de inibição do crescimento de Xanthomonas spp. in vitro foram utilizados os óleos essenciais, cravo da índia (Syzygium aromaticum) e erva cidreira (Melissa officinalis) sem e com adição de Tween 20\% (1:1); Tween 20\%; hidróxido de cobre (2 $\left.\mathrm{g} \mathrm{L}^{-1}\right)$; nas concentrações 100, 10, 1, 0,1 e 0,01\%; e água estéril como testemunha. Em placas de Petri foi adicionado uma camada básica de meio ágar-água $2 \%$ e outra camada contendo meio nutritivo semissólido $(0,8 \%)$ acrescida de $10 \%$ da suspensão bacteriana $\left(10^{8} \mathrm{UFC} \mathrm{mL}^{-1}\right)$. Em seguida, 2 discos de papel de filtro esterilizado, de $6 \mathrm{~mm}$ de diâmetro foram colocados sobre o meio e embebidos com $10 \mu \mathrm{L}$ de cada produto, nas diferentes concentrações, com 3 repetições para cada concentração e para cada produto. Após $48 \mathrm{~h}$ de incubação em estufa à $28^{\circ} \mathrm{C}$, foi observado a presença do halo de inibição.

Em casa de vegetação, plantas de tomate cv. Santa Cruz Kada foram cultivadas em vasos com capacidade de $500 \mathrm{~mL}$, com substrato de solo, areia, húmus e vermiculita (4:1:1:1). Após 28 dias da semeadura, as plantas (três a quatro folhas) foram pulverizadas até o ponto de escorrimento, com os óleos essenciais cravo da índia $\left(1 \mathrm{~mL} \mathrm{~L}^{-1}\right)$ e erva cidreira $\left(2 \mathrm{~mL} \mathrm{~L}^{-1}\right)$ com adição de Tween $20 \%$ (1:1); Tween $20 \%(2$ $\left.\mathrm{mL} \mathrm{L}^{-1}\right)$; hidróxido de cobre $\left(2 \mathrm{~g} \mathrm{~L}^{-1}\right)$ e água estéril (testemunha). Três dias depois, as plantas foram inoculadas por aspersão com a suspensão bacteriana $\left(10^{7} \mathrm{UFC} \mathrm{mL}^{-1}\right)$ e pulverizadas com os produtos em intervalos de 3, 6, 9 ou 12 dias. As plantas foram mantidas em câmara úmida 24 horas antes e após a inoculação.

A severidade da doença foi avaliada, aos 3, 6, 9, 12, 15, 18, 21, 24 e 27 após a inoculação empregando-se uma escala diagramática (7). A área abaixo da curva de progresso de severidade (AACPS) foi calculada pela fórmula: AACPS $=\sum\left(\left(\mathrm{Y}_{\mathrm{i}}+\mathrm{Y}_{\mathrm{i}+1}\right) / 2\right)\left(\mathrm{t}_{\mathrm{i}+1}-\mathrm{t}_{\mathrm{i}}\right)$, onde: $\mathrm{Y}$ representa a intensidade da doença; t o tempo e i representa o número de avaliações no tempo (2).

O experimento foi conduzido em esquema fatorial, composto de 5 produtos, 4 intervalos de aplicações (3, 6, 9 e 12 dias), com 4 blocos, sendo considerado como unidade experimental, um vaso contendo duas plantas. Os dados obtidos foram submetidos ao teste de KolmogorovSmirnov a $5 \%$ de probabilidade, à análise de variância e as médias comparadas pelo teste de Tukey a $5 \%$ de significância.

Os óleos essenciais cravo da índia e erva cidreira (Tabela 1), sem e com adição de Tween $20 \%$, assim como o hidróxido de cobre, nas concentrações 100 e 10\% inibiram o crescimento de Xanthomonas spp. in vitro. Nas demais concentrações ( 1 a $0,01 \%)$ não houve inibição do crescimento bacteriano, com exceção para hidróxido de cobre para a concentração $1 \%$. O Tween $20 \%$ em qualquer das concentrações não inibiu o crescimento bacteriano, da mesma forma a água usada como testemunha.

Diversos óleos essenciais descritos por Kotan et al. (4) e os óleos de cravo da índia e de canela (10) também inibiram o crescimento de Xanthomonas spp. in vitro. Os efeitos dos óleos são atribuídos aos compostos bioativos que possuem, como o eugenol, no cravo da índia (1) e o citral, na erva cidreira (12), as quais são substancias antimicrobianas. Assim, os óleos essenciais cravo da índia e erva cidreira inibiram o crescimento da Xanthomonas spp. in vitro, mostrando-se promissores para controle da bactéria.

Para a área abaixo da curva de progresso da severidade da mancha bacteriana do tomateiro (Tabela 1), o intervalo de três e seis dias de aplicação dos óleos essenciais, de cravo da índia e de erva cidreira reduziram significativamente a quantidade de doença, assim como o hidróxido de cobre, quando comparados com as plantas pulverizadas com água (testemunha). Somente a aplicação do hidróxido de cobre, a cada intervalo de nove dias reduziu significativamente a quantidade de doença, em relação a testemunha. O intervalo de pulverização dos

Tabela 1. Inibição do crescimento de Xanthomonas spp. in vitro, em diferentes concentrações dos óleos essenciais. Uberlândia, MG, 2017.

\begin{tabular}{|c|c|c|c|c|c|}
\hline \multirow{2}{*}{ Produtos } & \multicolumn{5}{|c|}{ Concentrações (\%) } \\
\hline & 100 & 10 & 1 & 0,1 & $\mathbf{0 , 0 1}$ \\
\hline Hidróxido de cobre & + & + & + & - & - \\
\hline Erva cidreira & + & + & - & - & - \\
\hline Cravo da índia + Tween $20 \%$ & + & + & - & - & - \\
\hline Água estéril & - & & & & \\
\hline
\end{tabular}

+= presença de halo; - = ausência de halo

Tabela 2. Área abaixo da curva de progresso da severidade da mancha bacteriana do tomateiro, em intervalos de aplicação de óleos essenciais. Uberlândia, MG, 2017.

\begin{tabular}{|c|c|c|c|c|}
\hline \multirow{2}{*}{ Produtos } & \multicolumn{4}{|c|}{ Intervalo de aplicação (dias) } \\
\hline & 3 & 6 & 9 & 12 \\
\hline Hidróxido de cobre & $17,75 \mathrm{aA}$ & $20,75 \mathrm{aA}$ & $19,13 \mathrm{aA}$ & $28,43 \mathrm{aB}$ \\
\hline Erva cidreira + Tween $20 \%$ & $26,10 \mathrm{bA}$ & $26,48 \mathrm{aA}$ & $33,30 \mathrm{bA}$ & $32,08 \mathrm{aA}$ \\
\hline Tween $20 \%$ & $37,23 \mathrm{cA}$ & $36,75 \mathrm{bA}$ & $37,18 \mathrm{bA}$ & $34,10 \mathrm{aA}$ \\
\hline
\end{tabular}

Médias seguidas por letras iguais minúsculas na coluna ou maiúsculas na linha, não diferem estatisticamente entre si, pelo teste de Tukey a 5\% de significância. 
produtos a cada 12 dias, não reduziu a quantidade da doença, não diferindo significativamente da testemunha. Portanto, o uso de óleos essenciais pode ser uma alternativa, para o manejo da mancha bacteriana do tomateiro, reduzindo a severidade da doença, quando aplicados em intervalos mais curtos, no caso de três e seis dias.

De acordo com Lucas (6) o óleo essencial cravo da índia apresentou proteção do tomateiro à Xanthomonas vesicatoria, pois este óleo degrada a parede celular da bactéria, levando a perdas de proteínas, consequentemente alterando a capacidade de locomoção da bactéria até os pontos de penetração. Além de ativar mecanismos de defesa da planta, devido aumento das enzimas peroxidase, quitinase e glucanase e a lignificação da parede celular, após o tomateiro ser pulverizado com óleo essencial cravo da índia e inoculado com a bactéria (6).

A eficácia de óleos essenciais inibindo o desenvolvimento de fitobactérias in vitro já foram descritas $(10,11)$, no entanto, informações práticas aplicadas em sistemas de produção são escassas.

Logo, o resultado deste trabalho torna-se aplicável em função do intervalo da pulverização do tomateiro, com os óleos essenciais, cravo da índia ou erva cidreira, no controle da mancha bacteriana do tomateiro, pois o efeito protetor de um indutor de resistência pode durar desde poucos dias até algumas semanas, dependendo do tipo do indutor e da planta utilizada (9). Neste caso, a pulverização do tomateiro em intervalos de três e seis dias foram eficientes para reduzir a severidade da mancha bacteriana do tomateiro. Os óleos essenciais podem ser utilizados principalmente em cultivo protegido, onde os aplicadores estão mais expostos a ação tóxica dos agroquímicos e também na agricultura orgânica, onde utiliza-se produtos naturais para o controle de doenças.

Assim, pode-se concluir que os óleos essenciais de cravo da índia e erva cidreira estudados, inibiram o crescimento de Xanthomonas spp. in vitro e reduziram a severidade da mancha bacteriana do tomateiro, podendo ser recomendados para o manejo da doença, com intervalos de aplicações a cada três e seis dias, reduzindo o uso de defensivos agrícolas e consequentemente o impacto ambiental.

\section{REFERÊNCIAS}

1. Abreu, C.L.M. de. Controle de Alternaria solani em tomateiro (Lycopersicon esculentum) com óleos essenciais. 2006. 71p. Tese (Doutorado em Agronomia), Universidade Estadual Paulista, Faculdade de Ciências Agronômicas, Botucatu.

2. Campbell, C.L.; Madden, L.V. Introduction to plant disease epidemiology. New York: Jonh Wiley, 1990. 532 p.

3. Jones, J.B.; Lacy, G.H.; Bouzar, H.; Stall, R.E.; Schaad, N.W. Reclassification of the xanthomonads associated with bacterial spot disease of tomato and pepper. Systematic of Applied Microbiology, Amsterdam, v.27, n.6, p.755-762, 2004.

4. Kotan, R.; Dadasoglu, F.; Kordali, S.; Cakir, A.; Dikbas, N.; Cakmacki, R. Antibacterial activity of essential oils extracted from some medicinal plants, carvacrol and thymol on Xanthomonas axonopodis pv. vesicatoria (Doidge) Dye causes bacterial spot disease on pepper and tomato. Journal of Agricultural Technology, Bangkok, v.3, n.2, p.299-306, 2007.

5. Kurozawa, C.; Pavan, M.A. Doenças do tomateiro (Lycopersicon esculentum). In: Kimati, H.; Amorim, L.; Rezende, J.A.M.; Bergamin Filho, A.; Camargo, L.E.A. Manual de fitopatologia: doenças das plantas cultivadas. 4.ed. São Paulo: Agronômica Ceres, v.2, p.607-626, 2005.

6. Lucas, G.C. Óleos essenciais no controle da mancha bacteriana do tomateiro. 2009. 93p. Dissertação (Mestrado em Fitopatologia), Universidade Federal de Lavras, Lavras.

7. Mello, S.C.; Takatsu, A.; Lopes, C.A. Escala diagramática para avaliação da mancha-bacteriana do tomateiro. Fitopatologia Brasileira, Brasília, v.22, n.3, p.447-448, 1997

8. Nascimento, A.R.; Fernandes, P.M.F.; Borges, L.C.; Moita, A.W.; Quezae do-Duval, A.M. Controle químico da mancha-bacteriana do tomate para processamento industrial em campo. Horticultura Brasileira, Brasília, v.31, n.1, p.15-24, 2013.

9. Pascolati, S.F. Fisiologia do parasitismo: como as plantas se defendem dos patógenos. In: Amorim. L., Rezende, J.A.M., Bergamin Filho, A. Manual de fitopatologia: princípios e conceitos. 4 ed. São Paulo: Agronômica Ceres, v.1, p. 593-636, 2011.

10. Pedrosa, F.P.C. Bioatividade de óleos essenciais frente a bactérias fitopatogênicas do tomate (Solanum lycopersicum L.). 2016. 71p. Dissertação (Mestrado em Ciências dos Alimentos), Universidade Estadual de Campinas, Campinas.

11. Silva, E.O.; Alves, E.; Ferreira, T.C.; Albuquerque, C.A.C. Óleos essenciais no controle da pinta bacteriana e na ativação de respostas bioquímicas em tomateiro. Summa Phytopathologica, Botucatu, v.43, n.3, p.212-217, 2017.

12. Silva, N.A.; Oliveira, F.F.; Costa, L.C.B.; Bizzo, H.R.; Oliveira, R.A. Caracterização química do óleo essencial da erva cidreira (Lippia alba (Mill.) NE Br.) cultivada em Ilhéus na Bahia. Revista Brasileira de Plantas Medicinais, Botucatu, v.8, n.3, p.52-55, 2006. 